\title{
Türkiye'de Politik Devir ve Devlet Borçları İlişkisi
}

\author{
DOI: $10.26466 /$ opus.702552
}

*

\section{Mehmet Ela *}

* Dr. Öğr. Üyesi, Osmaniye Korkut Ata Üniversitesi, İ.̇̇B.F, Kamu Yönetimi Böl., Osmaniye. E-Posta: mehmetela@osmaniye.edu.tr

ORCID: 0000-0001-7341-6312

\section{Öz}

Politik devir (iktidar değgişimi), birçok sosyoekonomik ve mali faktörü etkilemektedir. Politik devrin etkilediği faktörlerden bir tanesi ise devlet borç göstergeleridir. Politik devir, devlet yönetimine hangi partinin geleceği konusunda belirsizliğe yol açtığından, devlet borçlarına ilişkin göstergelerle ilişkilidir. Bu açıdan, çalışmada politik devirle ilişkili dört devlet borç göstergesi belirlenmiştir. Bu göstergeler, borç düzeyi (genel devlet borcu/GSYIH), borç krizi (kriz yılları), borç temerrüdü (temerrüt yılları) ve ülkenin kredibilitesinden (kredi notları) oluşmaktadır. Çalışmada grafiklerle desteklenen söylemsel bir yöntem benimsenmiş ve Türkiye için 1960-2019 yılları arasında, politik devir ve borç göstergeleri ilişkisi analiz edilmiştir. Çalışmanın sonucuna göre; (i) Türkiye'de yoğun politik devrin yaşandığı dönemlerin ardından borç düzeyi artışa geçmektedir. Politik istikrarm görüldü̆̆̈̈ dönemlerde ise borç düzeyleri düşmektedir. (ii) Türkiye'de yoğun politik devrin ardından borç krizi yaşanmakta, krizin ardından ise politik istikrar hüküm sürmektedir. Bu durum toplumun borç krizinin ardından siyasi istikrar istediği şeklinde yorumlanabilmektedir. (iii) Türkiye'de yoğun politik devrin yaşandığı yilların ardından temerrüt sayılarında artış görülmektedir. Temerrüt yıllarında veya temerrüdün ardından ise, nispeten siyasi istikrar yaşanmaktadır. (iv) Türkiye'de politik devir kredi derecelerini olumsuz etkilemektedir ancak etki sinırlıdir.

Anahtar Kelimeler: $\quad$ Iktidar değişimi, devlet borç göstergeleri, kamu yönetimi, kamu borç yönetimi, Türkiye 


\title{
The Relationship Between Political Turnover and Sovereign Debt in Turkey
}

\begin{abstract}
Political turnover (government change) affects many socio-economic and fiscal factors. One of the factors affected by the political turnover is the sovereign debt indicators. The political turnover is related to the indicators of sovereign debt as it causes uncertainty about which party will come into power. In this regard, four sovereign debt indicators related to political turnover were identified in the study. These indicators consist of debt level (general government debt / GDP), debt crisis (crisis years), debt default (default years) and the country's credibility (credit ratings). The study adopted a discursive method supported with graphs and analyzed the relationship of political turnover and debt indicators between the years of 1960-2019 for Turkey. According to the result of the study; (i) After the period of intense political turnover, level of debt increases in Turkey. In periods of political stability, debt level decreases. (ii) After the period of intense political turnover, the debt crises are experienced in Turkey and after the debt crisis, political stability prevails. This situation can be interpreted as the society wants political stability after the debt crisis. (iii) In Turkey, after years of intense political turnover, there is an increase in the number of debt defaults. In the period of default or after the default, political stability is experienced. (iv) Political turnover negatively affects credit ratings in Turkey, but the effect is limited.
\end{abstract}

Keywords: Government change, sovereign debt indicators, public administration, public debt management, Turkey. 


\section{Giriş}

Politik devir, birçok kaynakta lider değişimi, iktidar değişimi ve hükümet değişimi gibi farklı göstergelerle temsil edilmiştir. Çalışmamızda iktidar değişimini temsil eden politik devir, topluma ilişkin birçok faktörü etkileyebilme gücüne sahiptir. Nitekim politik devrin ekonomik, mali ve özellikle de sosyal etkilerinden bahsedebilmek mümkündür. Bu bağlamda politik devir yatırımcı davranışları, ticari ilişkiler, ekonomik büyüme, teknolojik değişim gibi toplumu ilgilendiren birçok faktör yelpazesini etkileyebilmektedir. Politik devrin etkilediği faktörlerden bir tanesi de hiç şüphesiz devlet borçlarına ilişkin olay ve göstergelerdir.

Politik devir, devlet borçlanmasını çeşitli biçimlerde etkileyebilmektedir. Politik devir, temelde yeniden seçilebilme ihtimali konusunda kısa görüşlü (miyop) olan partilerin varlığı nedeniyle devlet borçlanması üzerinde etki göstermektedir. Nitekim siyasi partiler, oluşan borçların gelecekteki sorumluluğu konusunda bilinmezlik yaşandığından dolayı borçlanmayı arttırabilmekte ya da tekrar seçilebilme ihtimalinin düşük olması sonucu halefini etkileyebilmek isteyen parti, borçlanma stratejisini değiştirebilmektedir. Bu durum ise aşırı borçlanmaya, borç krizleri ve temerrütlerine neden olabilmekte iken ülkelerin kredibilitesini olumsuz etkileyebilmektedir.

Politik devir, Türkiye gibi yüksek iktidar değişimine sahip bir ülke açısından özellikle önem arz etmektedir. Türkiye' de son dönem hariç olmak üzere oldukça yüksek olan politik devir, devlet borçlanması konusunda birtakım önemli sonuçlara yol açmıştır. Bu noktadan hareketle oluşturulan ve bu konuda Türkiye için yapılan ilk çalışma mahiyetindeki bu çalışmada, öncelikle teorik ve ampirik literatür incelenerek politik devrin hangi borç göstergelerini etkilediği belirlenmiştir. Elde edilen sonuca göre, politik devir, borçlanma düzeyi, borç temerrütleri ve krizleri ile ülke kredibilitesini etkilemektedir. Söz konusu bu borçlanma göstergeleri ve iktidar değişimi ile temsil edilen politik devir arasındaki ilişki ise Türkiye için grafiklerle desteklenen söylemsel bir yöntemle değerlendirilmiştir.

Çalışma, iki bölümden oluşmaktadır. Giriş bölümünün ardından ilk bölümde politik devir ve devlet borçları ilişkisi genel olarak ele alınmıştır. İkinci bölümde politik devir ve devlet borçları ilişkisi Türkiye için ele alınmış ve ardından sonuca gidilmiştir. 


\section{Politik Devir ve Devlet Borçları İlişkisi}

Politik devir birçok devlet borç göstergesini etkileyebilmektedir. Bu bölümde literatürde ele alınan ve politik devirle ilişkili olan borç göstergeleri sınıflandırılmış ve politik devirle ilişkilerine yönelik teorik ve ampirik literatür sunulmuştur.

\section{Politik Devir ve Borç Düzeyi İlişkisi}

Politik devir ve borç düzeyi ilişkisi 1990 'l y ylların başında tartışılmaya başlanmıştır. Bu dönemde çalışmalar öncelikle ilişkinin teorik boyutuna yer vermişlerdir. Daha sonraki dönemde ise konuya ilişkin ampirik literatür gelişmiştir. Söz konusu gelişmelere paralel olarak çalışmamızda öncelikle teorik literatür incelendikten sonra ampirik literatüre yer verilecektir.

Politik devir ve borçlanma düzeyi ilişkisini teorik açıdan ele alan ilk çalışmalardan birisi olan Alesina ve Tabellini (1990) tarafından ele alınan modele göre, iki farklı parti iki farklı kamu harcama kompozisyonunu tercih eden seçmen grubunu temsil etmektedir ve iki mal için yapılan kamu harcaması konusunda anlaşamamaktadır. Bu durumda ise, bütçe açık vermekte ve borçlanma seçmenlere fayda sağlayan optimal dengenin üzerine çıkmaktadır. Anlaşmazlık ve hangi partinin seçileceğinin bilinmemesi, partilerin diğer partinin seçilmesi halinde kendi istediği kamu harcaması türü yapılmadığı için, kamu harcamasının kompozisyonundan daha az marjinal fayda sağlayacağı anlamına gelmektedir. Diğer yandan bilinmezlik, yeni seçilecek hükümete borç bırakmanın yüksek vergi ve düşük kamu harcaması şeklindeki maliyetlerinin içselleştirilemeyeceği anlamına gelmektedir. Bu durumda borç düzeyi artmakta ve sosyal olarak optimal dengenin üzerine çıkmaktadır. Buna göre, parti gelecek dönemde seçilecek partinin kamu harcamasını etkilemek ve sınırlamak için daha fazla borçlanmaktadır. Borç düzeyi, alternatif partiler arasında çatışmanın artması ve yönetimdeki partinin tekrar seçilme ihtimalinin düşmesi ile birlikte daha da artmaktadır. Nitekim halef hükümetin daha az harcayabilmesi için daha çok borç bırakılmaktadır. Bu durum, daha fazla kamu borcu anlamına gelmektedir. Konuya benzer bir açıklama getiren Persson ve Svensson (1989) tarafindan ele alınan modele göre, kararlarında farklılık olan iki parti söz konusudur. Bu durumda, daha az vergi alan 
ve kamu harcaması yapan iktidar eğer daha fazla vergi alan ve kamu harcaması yapan genişletici politika izleyen bir hükümetin gelecek seçimi kazanacağına inanmakta ise borçlanmayı arttırmaktadır. İktidar, kendinin kazanacağını veya da kendinden daha az harcama yapan ve vergi alan bir hükümetin kazanacağını düşünür ise daha az borçlanmaktadır. Bu anlamda politik devir (iktidar değişimleri) kamu borçlanmasını arttırmaktadır. Grilli, Masciandaro ve Tabellini (1991) tarafından oluşturulan modele göre ise hükümet değişimleri gelecekteki borçların devralınıp devralınmamasına göre borçlanma düzeyini etkilemektedir. Buna göre, borçlanan hükümet, yeniden seçilmeyi beklemiyorsa, gelecekte, bugün çıkarılan borcu devralmayı beklemiyordur. Yeniden seçilme olasılığı ne kadar az olursa, borç alınan tutar da o kadar yüksek olmaktadır. Dolayısıyla bu yaklaşım, bir partiden veya lider grubundan diğerine daha sık iktidar değişikliği olan ülkelerde, yani politik olarak daha istikrarsız ortamlarda, kamu borcunun daha büyük olacağını öngörmektedir. Debortoli ve Nunes (2008) tarafından oluşturulan ve hükümetlerin gelecek politikalarına bağlılığının olmaması ve partiler arası tercih farklılıklarının borçlanmaya etkisini ele alan modele göre, iktidar değişimleri borçlanma düzeyi üzerinde etkili değildir. Bu durumun nedeni ise borç düzeyi ile iktidar değişimi ilişkisinin belirsiz ve etkinin önemsiz derecede olmasıdır. Bu nedenle, partiler arası gruplaşma ve hükümet değişimi etkileri ayrı ayrı ele alınmalıdır. Çalışmaya göre nitekim etkinin derecesi taraflar -partilerarası çatışmanın derecesine bağlıdır.

Teorik literatüre politik miyopluk açısından yaklaşan çalışmalardan Grechyna (2015)'in açıklamasına göre, yeniden seçilme beklentileri hakkındaki belirsizlik, hükümetin gelecek faydalarının şimdiki değerini azaltarak, hane halkına göre iktidarı miyop hale getirmekte ve kamu sektörü tarafından aşırı borçlanmaya ve fazla harcamaya neden olmaktadır. Benzer bir açıklama yapan Di Bartolomeo, Di Pietro, Saltari ve Semmler (2018)'e göre ise politikacılar kısa vadede sınırlı bilgi ile işlem yapmakta ve karar verirlerken politikalarının ve diğer partilerin politikalarının uzun vadeli etkisini öngörememektedirler. Bu nedenle özensizdirler ve rasyonel değildirler. Politika miyopluğu, politika yapıcıları başlangıçta borcun istikrara kavuşması konusunda daha agresif olmaya itmekte, ancak sonunda, uzun vadede aşırı kamu borcuna yol açmaktadır. Miyop politika yapıcılar, kısa görüşlü olmaları nedeniyle, baş- 
langıçta borcu önemli ölçüde azaltan agresif politikalar uygulamaktadır; ancak, bu politikalar uzun vadede eylemsizlik sonucunda yüksek borçlanmaya neden olmaktadır.

Politik devir ve borçlanma düzeyi ilişkisini ampirik açıdan ele alan çalışmalara bakıldığında, Grilli vd. (1991), 15 ülkeyi 1970-1989 dönemi için ele almıştır. Sonuca göre, devlet borç birikimi, ortalama hükümet dayanıklılığı (iktidarda kalma süresi) ile güçlü bir şekilde ilişkilidir. Franzese (2001) tarafından yapılan ve 20 ülkeyi 1956-1990 döneminde ele alan çalışmaya göre, seçim sıklı̆g 1 arttıkça borç düzeyi de artmaktadır. Alt ve Lassen (2006), 19 OECD ülkesini 1989-1998 dönemi için ele alan çalışmalarında politik devrin borç düzeyini azalttığı sonucuna ulaşmıştır. Grechyna (2015)'nın 1995-2007 döneminde 20 gelişmiş ülkeyi ele alan çalışmasına göre politik devir borç seviyesini arttırmaktadır. Hanusch ve Vaaler (2015), 53 ülkeyi 2002-2011 dönemi için ele almıştır. Sonuca göre, daha az kamu borcu ve daha düşük mali açıkları olan ülkelerde hükümet devir hızı daha düşüktür. Park (2018), 1993-2012 dönemi için 108 bağımsız yetkileri olan hükümet kuruluşunu ele almıştır. Çalışmaya göre politik devir (lider değişimi) kısa vadede borç düzeyini arttırmaktadır.

\section{Politik Devir ve Borç Krizi İlişkisi}

Politik devir ve borç krizi ilişkisini ele alan literatür hacmi oldukça sınırlıdır. Politik devrin diğer borç göstergeleri ile ilişkisini ele alan çalışmaların aksine borç krizi-politik devir ilişkisi ancak 2000'li yıllarda kendisine literatürde yer bulabilmiştir.

Politik devir ve borç krizi birbirini karşılıklı olarak etkileyebilmektedir. Bir yandan borç krizi politik devri hızlandırabilirken diğer yandan politik devir de borç krizine yol açabilmektedir (Chwieroth ve Walter, 2010). Söz konusu ilişkiyi ele alan çalışmalara bakıldığında, Manasse, Roubini ve Schimmelpfennig (2003), 47 ülkeyi 1970-2002 yılları için inceleyen çalışmasında, başkanlık seçimi olan yıllarda ülkelerin borç krizine girme ve krizde kalma olasılı̆̆1nın arttı̆̆ 1 sonucuna ulaşmıştır. Bu anlamda seçimler, krizi beslemektedir. Bir diğer çalışma olan Chwieroth ve Walter (2010), çalışmalarında 160 ülkeyi 1800 ile 2006 yılları arası dönem için analiz etmiştir. Sonuca göre, finansal krizler ve politik devir (iktidar değişimleri) birbirini karşılıklı olarak etkilemektedir. Ancak krizler politik devir olasılığını, politik devrin kriz olasılığını 
arttırdığından daha çok arttırmaktadır. Ayrıca, krizler içinde politik devir ile en güçlü ilişkiyi borç krizleri sağlamaktadır. Son olarak Pepinsky (2012), global finansal kriz ve politik devir ilişkisini ele alan çalışmasında şu sonuca ulaşmıştır: Kriz ve politik devir ilişkisi, krizin hükümetin politikaları sonucunda çıkıp çıkmadığı ya da dış ülkeler kaynaklı olup olmadığı, ülkelerin krize cevabı, politik kurumların rolü ve krizin etki derecesine göre değişmekte ve şekillenmektedir.

\section{Politik Devir ve Temerrüt İlişkisi}

Politik devir ve temerrüt ilişkisini ele alan teorik çalışmalar öncelikle politik devrin yüksek borçlanma maliyetleri yoluyla borçlarda temerrüdü (iç borçlanmada konsolidasyon ve diş borçlanmada moratoryum) arttıracağından hareket etmektedirler. Bu konuda Cuadra ve Sapriza (2008)'ya göre, politik istikrarsızlık kısa görüşlü (miyop) hükümetlere yol açmaktadır. Gelecekteki tüketimin bugünkü (iskonto) değerinin düşük olması, temerrüt teşviklerini arttırmaktadır. Bu, herhangi bir borçlanma seviyesi için daha yüksek faiz oranlarına yol açmakta ve sonuçta, politik devirde artış ve iktidar süresinde kısalma, daha yüksek temerrüt ve faiz farkına (spread) yol açmaktadır. Konuyu benzer şekilde ele alan Scholl (2017)'nin modeline göre, politik devir, tarafların (partilerin) borçlanma ile temerrüt politikaları konusundaki farklılıklarını arttırmaktadır. Siyasi belirsizlik olduğunda, yani kimin seçileceğinin belirli olmaması durumunda, daha düşük kamu harcamasını tercih eden parti, seçim avantajını artırmak için daha az borç almakta ve daha az temerrüde düşmektedir. Buna karşılık, daha yüksek kamu harcamasını tercih eden parti borçlanmaktadır ve temerrüde düşmesi için daha büyük teşvikleri vardır. Şöyle ki, seçilme ihtimalini arttırmak isteyen ve daha az harcama seçen taraf, daha fazla borçlanma kabiliyetine sahiptir ve daha az temerrüde düşer. Böylece daha fazla seçilme olasılığına kavuşur. Aynı amaçla daha fazla harcama yapan taraf borçlanma konusunda kısıtlıdır, bu anlamda daha yüksek kredi maliyetleri ile karşılaşır ve daha fazla temerrüde düşer.

Bazı teorik çalışmalar ise politik devir ve borç temerrüdü ilişkisini demokrasi ve otokrasiler açısından karşılaştırmıştır. Bu çalışmalardan Amador (2003)'e göre, siyasi belirsizlikte artış, partilerin borçlanmayı sürdürme yeteneğini arttırmaktadır. Buna göre, demokraside politik devir, borçların sürdürülebilirliği ile pozitif yönde ilişkilidir. Otokraside ise politik devir yoktur ve 
bu nedenle politik devir borçların sürdürülebilirliği ile ilişkili değildir. Otokrasilerde temerrüt kaçınılmaz iken demokrasiler daha az temerrüde düşmektedir. Konuyu aksi yönde ele alan bir modelleme yapan Dhillon ve Sjostrom (2009)'a göre ise, demokrasilerde diktatörlüğe kıyasla daha yüksek politik devir, geri ödeme teşviklerinin düşük olduğunu göstermektedir. Burada ahlaki tehlike problemi vardır ve buna göre demokrasilerde hükümet gelecekte değişebilecektir.

Bazı teorik çalışmalar ise politik devir ve borç temerrüdü ilişkisini temerrüt dönemindeki ekonomik koşulları gözeterek modellemiştir. Bu konuda Hatchondo, Martinez ve Sapriza (2009)'a göre temerrüt, hükümetlerin görev süreleri boyunca kötü ekonomik koşullarla karşılaşması halinde, politik devir (iktidar değişimi) ile sonuçlanmaktadır. Öte yandan, politik değişim, iyi ekonomik koşullara sahip olunduğunda temerrüde neden olmamaktadır. Asiri ve Hubail (2014)'in değerlendirmesine göre ise politik istikrarsızlık, uzun vadeli sermaye akımlarındaki bir düşüş ve kreditörlerin vadesi gelen kredilerin vadesini uzatma isteksizliği gibi nedenlerle borç servisi sorunlarını dolaylı yoldan artırabilir. Bir süre boyunca, politik istikrarsızlık, ekonomik büyümeyi yavaşlatabilir, enflasyonu, iç darboğazları ve üretim sıkıntısını artırabilir ve ihracat ile ithalat arasındaki dengesizlikten dolayı döviz açı̆̆ı yaratabilir. Bu anlamda politik istikrarsızlık, ekonomiyi olumsuz etkileyerek borç ödeme gücünü düşürebilir.

Politik devir ve temerrüt ilişkisini ampirik açından ele alan çalışmalara bakıldığında, Bordo ve Oosterlinck (2005), 1880-1913 dönemi için 29 ülkeyi ele almış ve politik istikrar (iktidar değişimlerinin az olması) ve temerrüt ilişkisini araştırmıştır. Çalışmanın sonucuna göre, politik istikrarsızlık temerrüde neden olmakta ve temerrüt de politik istikrarsızlığa neden olmaktadır. Ancak bu ilişki çok güçlü değildir ve ilişkide ekonomik faktörlerin önemi vurgulanmaktadır. Ayrıca Türkiye için temerrütleri açıklamada politik istikrarsızlık önemli bir konumdadır. Türkiye temerrütten bir sonraki yıl iktidar değişimi yaşamıştır. Türkiye'nin yaşadığı temerrüt sonrası politik devir sıklığı çalışmada ele alınan ülkelere göre daha yüksektir. Yu (2016), 1970-2010 yılları arasında 68 gelişmiş ve gelişmekte olan ülkeyi ele alan çalışmasında, yüksek politik devrin (liderlik süresi vb. koşullar) temerrüde düşme olasılığını arttırdığı sonucuna ulaşmıştır. Latin Amerika'daki borç temerrütlerini ele alan Cole, Dow ve English (1995)'un bulgusuna göre, Latin Amerika'da yaşanan temerrütler olan 1820 ve 1870'lerdeki iki temerrüt dalgası, bölgedeki yaygın siyasi 
istikrarsızlık dönemleriyle ilişkilidir. Citron ve Nickelsburg (1987)'nin 19601983 arasında 5 ülkeyi ele alan çalışmasına göre, politik istikrarsızlık, temerrüt olasılığını arttırmaktadır. Bu durum yeni hükümetlerin daha zayıf göstergelere sahip olduğu ve borçları ödeme konusunda daha isteksiz olduğu şeklinde yorumlanmıştır. Farklı beş ülkede yaşanan temerrütleri inceleyen Hatchondo ve Martinez (2010)'a göre sadece Arjantin'de yaşanan temerrüdün zamanının belirlenmesinde politik devir önemli bir faktör olarak öne çımıştır. Bu anlamda 2001 Arjantin temerrüdü, politik devir tarafından tetiklenmiştir. Livshits, Phan ve Trebesch (2014), 84 ülkeyi 1980-2012 dönemi için ele almış ve temerrütlerin maliye bakanının değişmesine neden olduğu sonucuna ulaşmıştır.

Bazı ampirik çalışmalar borç krizinden bir adım öteye giderek politik devir ile borç yeniden yapılandırmaları ve müzakereleri ilişkisini incelemiştir. Bu konuda Trebesch (2018), 1978-2010 döneminde 179 kamu borç müzakeresini ele almıştır. Sonuca göre politik devir, krizin çözüm sürecini bozmakta ve borç yeniden yapılandırma müzakere sürelerini uzatmaktadır. Balkan (1992), 31 ülkeyi 1971-1984 döneminde ele alan çalışmasında politik istikrarsızlık indeksindeki artışın borçları yeniden yapılandırma ihtimalini arttırdığı sonucuna ulaşmıştır. Bu bulguların aksine, 80 ülkeyi 1980-1990 dönemi için inceleyen Rivoli ve Brewer (1997)'ye göre, politik dönüşüm (lider veya iktidar değişimi) borçları yeniden yapılandırma riskini etkilememektedir.

Bazı ampirik çalışmalar, borç temerrütlerini iç ve dış borç temerrüdü olarak ikiye ayırarak politik devir ile ilişkilerini incelemiştir. Bu konuda, Lvovskiy (2018), 1875-2015 dönemi için 180 ülkeyi ele almıştır. Sonuca göre sadece iç borçta temerrüt iktidar değişimi olasılığını arttırırken dış borç temerrüdü iktidar değişimini etkilememektedir. Çünkü dış borç temerrüdü, seçmenleri doğrudan etkilememektedir.

Bazı ampirik çalışmalar ise, politik devir ve temerrüt ilişkisini demokrasiler için ayırmıştır. Bu çalışmalardan, Borensztein ve Panizza (2009)'a göre, diktatörlüklerde ekonomi politikası yapıcıların değişimi temerrütlerin ardından daha yüksektir. Bu, diktatörlüklerde bakanlıkları suçlama ve cezalandırmanın daha kolay olduğunu göstermektedir. Genelde ise, bu anlamda demokrasiler ve diktatörlükler birlikte ele alınırsa, temerrütlerin ardından iktidar değişimlerinde keskin bir artış vardır. Kohlscheen (2010)'in 59 ülkeyi 1976-2003 dönemi için ele alan çalışmasına göre ise düşük lider değişimi, 
borçları yeniden yapılandırma eğilimini ve temerrüdü azaltmaktadır. Demokrasilerde ise başkanlıklara göre yüksek politik değişime rağmen borçları yeniden yapılandırma düşüktür.

\section{Politik Devir ve Kredibilite İlişkisi}

Politik devir, ülkelerin kredibilitesinin göstergeleri olan kredi dereceleri, risk primleri ve tahvil indeksi ile ilişki içinde olabilmektedir. Bu konudaki teorik yaklaşımlara bakıldığında, Cuadra ve Sapriza (2008)'e göre, politik istikrarsızlık miyop hükümetlere yol açmakta ve temerrüde düşme olasılığını arttırmaktadır. Bu durum ise herhangi bir borçlanma seviyesi için daha yüksek faiz oranlarına yol açmaktadır. Politik devir ve kredibilite ilişkisini demokrasi ve otokrasiler için ayıran, geniş bir teorik değerlendirme yapan ve politik devri lider değişimi ile eşanlı tutan McGillivray ve Smith (2003)'e göre, liderlerin demokrasilerde değişmesi kolaydır. Eğer kreditörler temerrüde düşmüş olan ülkelere borç vermeyi reddederse, vatandaşlar temerrüde düşmüş liderleri görevden alırlar. Bu mekanizma, kredibiliteyi yeniden sağlamak için bir araç sunmanın ötesinde, yönetimde kalmak isteyen liderlerin en başta temerrüde düşmemelerini sağlar. Temerrüt riskinin asgari düzeyde olması nedeniyle, bu tür hükümetler uygun şartlarda borçlanabilir ve liderlik değişiminin kredibilite üzerinde minimum etkisi vardır. Buna karşllık, liderin değişmesi zor olduğunda, hükümetler görev sürelerini tehlikeye atmadan temerrüde düş̧ebilirler. Devlet borcunu geri ödemeye yönelik kurumsal bağlılık olmad1ğından, kredi güvenilirliği ekonomik koşullara ve liderlerin bireysel özelliklerine bağlıdır. Mutlak liderleri olan uluslar sadece krediye daha kötü erişim sağlamakla kalmaz, aynı zamanda liderlik değişimleriyle kredi değerlilikleri de değişir.

Politik devir ile kredibilite ilişkisini çeşitli göstergelerle ele alan geniş bir ampirik literatür söz konusudur. Bu konuda, Cotoc, Johri ve Sosa-Padilla (2018), 23 yıllık dönem için 63 ülkeyi ele alan çalışmalarında politik devrin devlet tahvil fiyatlarını düşürdüğü sonucuna ulaşmıştır. Block ve Vaaler (2004), 19 ülkeyi 1987-1999 dönemi için ele almıştır. Sonuca göre kredi derecelendirme kuruluşları, seçim yıllarında ülke notlarını daha sık değiştirmekte ve yaklaşık bir derece düşürmektedir; tahvil marjları (spreadleri) seçimden önceki 60 gün içinde, seçimden sonraki 60 gün içindeki marjlara göre daha yüksektir. Krueger ve Walker (2008), 1995-2000 döneminde 44 ABD eyaletini 
ele alan çalışmasında yüksek lider değişiminin tahvil riskini arttırdığı bulgusuna ulaşmıştır. Krueger ve Walker (2010), 2004-2007 dönemi için 40 eyaleti ele almış ve şu sonuca ulaşmıştır: Alt meclisteki devir (değişim), kredi kalitesi üzerinde pozitif etkiye sahiptir. Born, Müller, Pfeifer ve Wellmann (2018), 38 ülkeyi 1990 ve 2000'lerin verileriyle analiz etmiş ve tahvil marjlarındaki önemli artışların hükümetin değişme ihtimalini arttırdığı sonucuna ulaşmıştır. Jimenez (2011), 1999-2011 dönemi için 18 eyaleti ele alan çalışmasında vali değişimi ile tahvil dereceleri arasında ters yönlü ilişki elde etmiştir. Smaoui, Boubakri ve Cosset (2017)'in 35 gelişen piyasa ekonomisini 1993-2009 döneminde ele alan çalışmasına göre, politik istikrar (daha uzun dönem lider ve hükümet süresi) kamu tahvil marjların düşürmektedir. Asiri ve Hubail (2014), 70 ülkeyi 2006-2011 döneminde ele alan çalışmasında politik istikrarsızlığın ülke riskini arttırdığı ve kredibilitesini düşürdüğü sonucuna ulaşmıştır. Goretti (2005), 2002 yılında yer alan politik olayları örnek olay olarak seçmiştir. Çalışmaya göre, Brezilya'da politik belirsizlik borçlanma marjlarını arttırmıştır. Wang ve Tu (2014), Birleşmiş Milletler üyelerini 1995-2012 dönemi için ele almış ve lider değişikliğinin kredi derecesi üzerinde pozitif yönde etkili olduğunu bulmuştur. Ancak yarı başkanlık sisteminde lider değişikliği kredi derecesi üzerinde negatif etkili iken beşerî sermayesi gelişmiş ülkelerde etki anlamsızdır.

Bazı ampirik çalışmalar, politik devir ve kredibilite ilişkisini demokrasi vurgusu ile ele almışlardır. Bu çalışmalardan McGillivray ve Smith (2003)'in ABD doları cinsinden tahvil endekslerini kullanarak (J.P. Morgan) elde ettiği bulguya göre, demokratik devletlerde tahvil endeksleri üzerinde lider değişikliğinin hiçbir etkisi yoktur. Aksine, lider değişiminin daha zor olduğu otokratik devletlerde, lider değişikliğinin devlet tahvillerin fiyatı ve fiyat oynaklığı üzerinde büyük etkileri vardır. Özellikle, en otokratik devletlerde lider değişimi tahvil endekslerini ortalama \%10 azaltmaktadır. Glaurdić, Lesschaeve ve Vizek (2019), AB ülkelerini son 20 yıl için değerlendiren çalışmasında, pekişmiş demokrasilerde meclis seçiminin borç marjlarını (spreadlerini) pekişmemiş demokrasilere göre daha az etkilediği, meclis seçimlerinin daha sık olduğu pekişmemiş demokrasilerde marjların daha fazla arttığı sonucuna ulaşmıştır.

Bazı ampirik çalışmalar ise, sağ ve sol kanat partileri politik devir-kredibilite ilişkisi açısından ele almıştır. Bu çalışmalardan Vaaler, Schrage ve Block 
(2005), 1994'ten 2000'e kadar 12 gelişmekte olan ülkede 19 seçimi değerlendirmiştir. Bulgusal olarak, sağ-kanat (sol-kanat) siyasi görevlilerin yerini sol-kanat (sağ-kanat) rakipleriyle değiştirmesi daha muhtemel olduğunda, tahvil sahipleri daha yüksek (düşük) yatırım riski algılayarak devlet tahvillerinde yüksek (düşük) kredi marjları (spread) talep etmektedir.

Bazı ampirik çalışmalar ise politik devir ve ekonomik faktörlerin kredibiliteyi açıklayıcılık gücüne vurgu yapmıştır. Bu konuda, Brewer ve Rivoli (1990), 30 çok borçlu ülkeyi 1975-1986 dönemi için ele almıştır. Sonuca göre, politik devir kredibiliteyi (kredi derecesi) açıklamada ekonomik faktörlerden daha etkilidir.

\section{Türkiye'de Politik Devir ve Devlet Borçları İlişkisi}

Bu bölümde Türkiye için, politik devir ve devlet borç göstergeleri (veya olayları) arasındaki ilişki daha önce belirlenen devlet borç göstergeleri temelinde söylemsel bir yöntemle analiz edilmiştir.

\section{Politik Devir ve Borç Düzeyi İlişkisi}

Politik devir ve borçlanma düzeyi ilişkisini ele alan literatüre bakıldığında gerek teorik gerekse de ampirik olarak, politik devrin borçlanma düzeyini arttıracağı görüşünün baskın olduğu görülmektedir. Ancak azınlıkta da olsa politik devir ile borçlanma düzeyi ilişkinin olmadığı ya da ilişkinin negatif yönde olduğu yönündeki görüşlerin de dikkate alınması gerekmektedir. Bu açıdan söz konusu ilişki, Türkiye için önem arz etmekte ve aşağıda bu ilişkinin boyutları açıklanmaya çalışılmaktadır. 


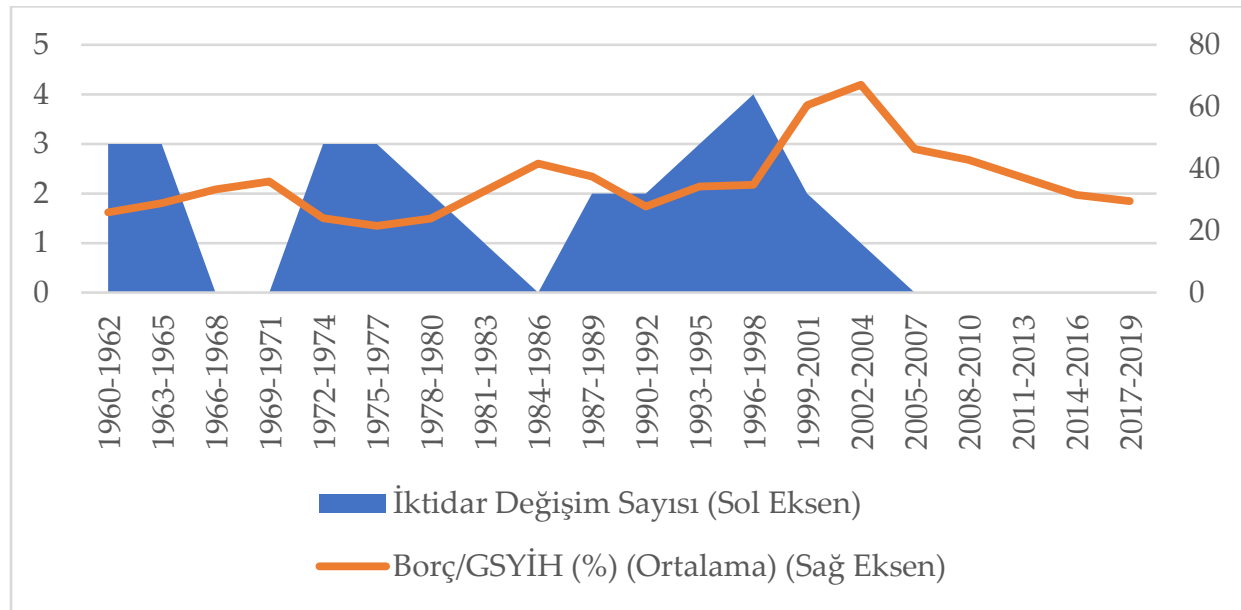

Grafik 1. Türkiye'de İktidar Değişimleri ve Borç/GSYïH Oranı (\%) (1960-2019) (Kaynak: IMF (2020); Netdata (2020))

Grafik 1'de Türkiye'de politik devrin göstergesi olarak alınan iktidar değişimleri sayıları ve borçlanma düzeyinin göstergesi olarak alınan devlet borçlarının GSYİH içindeki payı (borç/GSYİH) arasındaki ilişki ele alınmıştır. Verilerin ulaşılabilirliği dikkate alınarak Grafik 1'deki veriler 1960-2019 dönemini kapsamaktadır. Veriler, 1960 yılından başlamak üzere, üçer yıllık iktidar değişimi sayılarını ve genel devlet borcu/GSYİH (\%) ortalamasını içermektedir. Grafik 1'den görüldüğü üzere, iktidar değişiminin sıkça yaşandığ 1 dönemlerin ardından borçlanma düzeyinde önemli artışlar meydana gelmektedir. Nitekim 1960-1965 döneminde yaşanan 6 iktidar değişikliğinin ardından 1966-1971 döneminde artışa geçen borç/GSYİH oranları, 1969-1971 döneminde \%35 seviyelerine ulaşmıştır. İlerleyen dönemlerde ise iktidar değişiminin sıkça yaşandığı dönemlerin ardından borçlanma düzeyinde yaşanan artışlar daha belirgindir. Nitekim 1972-1983 döneminde yaşanan 7 iktidar değişikliğinin ardından 1981-1986 döneminde artışa geçen borç/GSYİH oranları yine 1987-2004 döneminde yaşanan iktidar değişimindeki artışın ardından yükselişe geçmiştir. Bu durum Türkiye'de siyasi istikrarsızlıkların faiz ve vade gibi borçlanma yapısı ve dolayısıyla borç stoku üzerinde etkili olduğunu göstermektedir (Ulusoy, 2012, s.103,107). Bunun dişında iktidar değişimlerinin nispeten daha düşük olduğu dönemlerin hemen ardından 
borç/GSYİH düzeyinde düşüş görülmektedir. Öyle ki, siyasi istikrarın yaşandığı 1969-1971 döneminin ardından düşüşe geçen borç/GSYİH oranları aynı şekilde 1984-1986 döneminde yaşanan siyasi istikrarın ardından düşüş eğilimi göstermiştir. Nispeten siyasi istikrarın görüldüğü son dönemde ise borç düzeyinde önemli derecede düşüş göze çarpmaktadır. Bu durumda, Türkiye için iktidar değişimlerinin (politik devrin) kendini izleyen dönemlerde borçlanma düzeyinde artş̧a neden olduğu ve politik istikrarın borç düzeyinde düşüşe neden olduğu söylenebilmektedir.

\section{Politik Devir ve Borç Krizi İlişkisi}

Türkiye, çeşitli kaynaklara göre, geçmiş dönemde borç krizleri yaşamıştır. Bu kaynaklardan Furceri ve Zdzienicka (2012)'ye göre, Türkiye 1978 yılında borç krizine girmişken, Manasse vd. (2003)'e göre, Türkiye 1978-1983 ve 20002002 dönemlerinde borç krizi yaşamıştır.

Grafik 2'de Manasse vd. (2003)'ü takiben borç krizi dönemleri belirlenmiş, borç krizleri yaşanan dönem ile krizlerin beş yıl öncesi ve sonrası dönemlerdeki iktidar değişimi verileri kullanılmıştır.

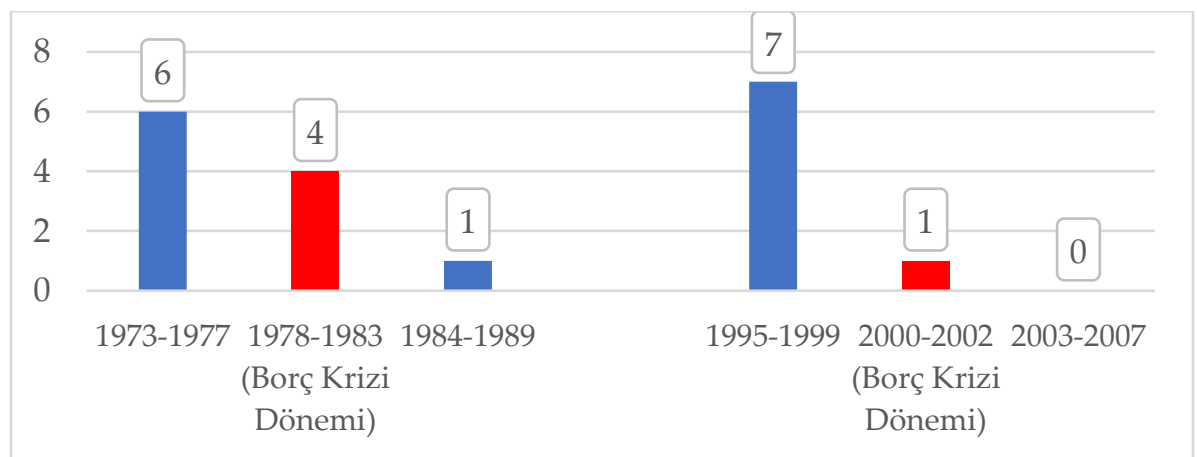

Grafik 2. Türkiye'de Borç Krizi Dönemleri ve Politik Devir (1973-1989, 1995-2007) (Kaynak: Manasse vd. (2003, s.9); Netdata (2020))

Grafik 2'den görüldüğ̈̈ü üzere Türkiye'de borç krizleri yoğun politik devir sonrasında vuku bulmuştur. Nitekim 1973-1977 döneminde 6 iktidar değişiminin ardından borç krizi yaşanırken 1995-1999 döneminde 7 iktidar değişiminin ardından borç krizi yaşanmıştır. Bu durum Türkiye'de politik devrin borç krizine neden olduğunu göstermektedir. Grafik 2' den görülen diğer bir 
özellik borç krizlerinin ardından politik devrin oldukça düşük seviyelerde kalmasıdır. Nitekim 1978-1983 krizinin ardından 1984-1989 döneminde sadece 1 iktidar değişimi yaşanmışken aynı şekilde 2000-2002 krizinin ardından 2003-2007 döneminde iktidar değişimi yaşanmamıştır. Sonuç olarak Türkiye'de politik devrin borç krizine neden olduğu ancak borç krizinin politik devri arttırmadığı söylenebilmektedir.

\section{Politik Devir ve Temerrüt İlişkisi}

Türkiye geçmiş bazı dönemlerde borçlarını geri ödeme konusunda problemler yaşamış ve temerrüde düşmüştür. Söz konusu temerrütler genellikle 1970'li ve 1980'li yıllarda yoğunlaşmıştır. Politik devir (iktidar değişimi) ise bazı dönemlerde yoğun iken bazı dönemlerde sınırlı kalmıştır. Bu duruma ilişkin göstergeler ise Grafik 3'te ele alınmıştır.

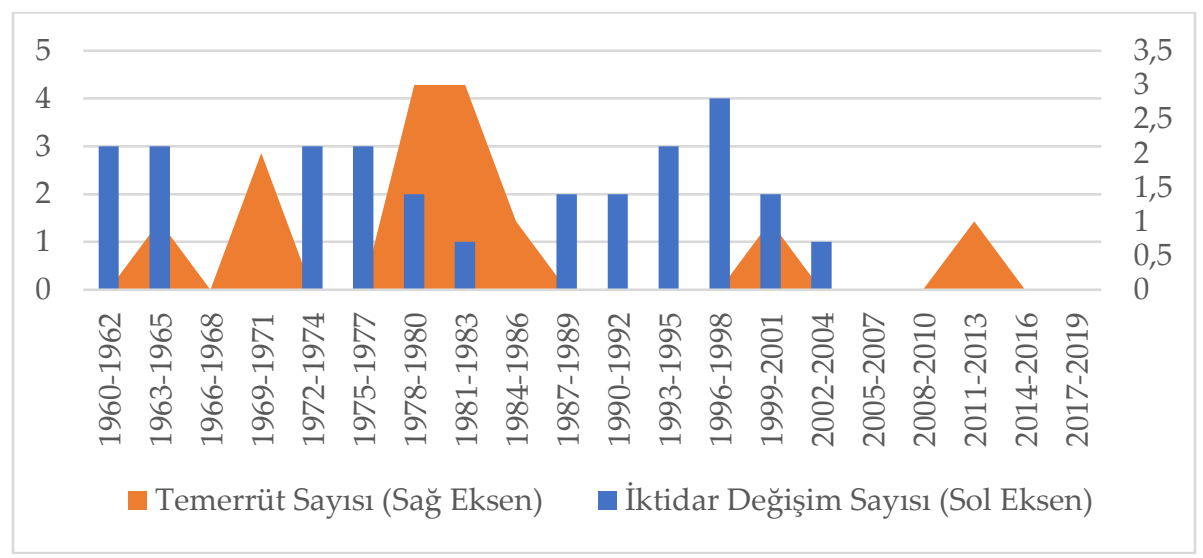

Grafik 3. Türkiye'de Temerrüt ve Politik Devir (1960-2019) (Kaynak: BoC-BoE Sovereign Default Database (2019); Netdata (2020)

Grafik 3'te verilerin ulaşılabilirliği de göz önüne alınarak 1960-2019 dönemindeki temerrüt sayıları ve iktidar değişimleri ile gösterilen politik devir, üçer yıllık gruplara ayrılmıştır. Grafik 3'e göre yoğun politik devrin yaşandığ 1 yılların ardından temerrüt sayılarında artış göze çarpmaktadır. Nitekim 1960-1968 döneminde yaşanan yüksek politik devrin ardından 1969-1971 döneminde 2 kez temerrüde düşülmüsstür. Ancak, BoC-BoE Sovereign Default Database (2019)'a göre temerrüde düşülen miktar düşüktür. Benzer şekilde 
1972-1980 dönemindeki oldukça yoğun politik devrin ardından 1978-1986 döneminde 7 kez temerrüde düşülmüştür ve temerrüde düşülen borç miktarı oldukça yüksektir. 1993-1998 döneminde yaşanan 7 iktidar değişiminin ardından ise 1999-2001 döneminde 1 kez temerrüde düşülmüştür. Grafik 3'ten görülen diğer bir durum ise temerrüt yıllarında veya temerrüdün ardından nispeten siyasi istikrarın yaşandığıdır. Bu anlamda sonuç olarak Türkiye'de politik devir, devlet borç temerrütlerini beslemektedir.

\section{Politik Devir ve Kredibilite İlişkisi}

Türkiye'de politik devir ve kredibilite ilişkisini ele almak üzere verilerin ulaşılabilirliği göz önüne alınarak literatürde sıkça kullanılan ve ülke riskini yansıtan tahvil endeksi, tahvil marjları (spreadleri) ve kredi derecelerinden gösterge olarak kredi dereceleri alınmıştır. Bunun nedeni ise geçmişe dönük en uzun verinin Moody's (2019) tarafından Türkiye için yayınlanan (Fitch ve S\&P daha geç bir dönemde derece vermeye başlamıştır) yabancı para cinsinden kredi notlarının olmasıdır. Politik devir göstergesi olarak ise iktidar değişimleri alınmıştır.

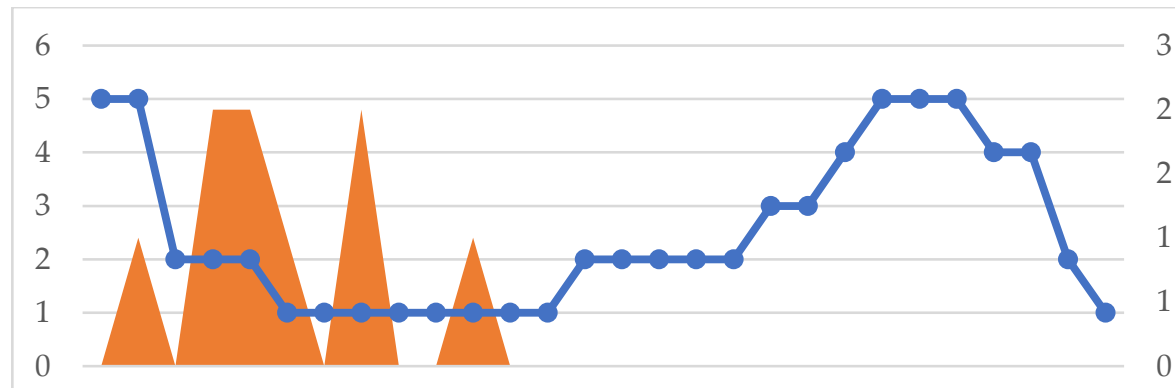

19921994199619982000200220042006200820102012201420162018

İktidar Değişimi Sayısı (Sol Eksen) — - Kredi Derecesi (Sağ Eksen)

Grafik 4. Türkiye'de Kredi Dereceleri ve Politik Devir (1992-2019) (Kaynak: Moody's (2019); Netdata (2020)) ${ }^{1}$

\footnotetext{
${ }^{1}$ Not: Kredi dereceleri için sol eksende 5:Baa3, 4:Ba1, 3:Ba2, 2:Ba3, 1:B1'dir.
} 
Grafik 4'e göre Türkiye yüksek politik devrin yaşandığg dönemlerde kredi derecesinde önemli düşüşler yaşamıştır. Nitekim 1993 yılındaki iktidar değişiminin ardından kredi notu 3 derece birden düşmüştür. 1995 ve 1996 yıllarındaki ikişer iktidar değişimi karşısında kredi derecesi 1 derece daha düşmüştür. Bundan sonraki dönemde ise 1999 ve 2002 dönemindeki iktidar değişimleri karşısında kredi notu tepkisiz kalmıştır. Nispeten siyasi istikrarın sağlandığı 2002 yılı sonrasında ise kredi dereceleri dalgalanmış, bu anlamda 2014 yılına kadar artarken son dönemde düşmüştür.

Politik unsurların Türkiye'nin kredi derecesi üzerindeki 1lımlı etkisi kredi derecelendirme kuruluşlarının devletleri derecelendirme metodolojisi içinde politik unsurların 15'e yakın faktör içinde sadece 1 faktörü oluşturmasından kaynaklanmaktadır. Nitekim derecelendirmeyi etkileyen faktörler arasında kurumsal, mali ve ekonomik faktörler gibi faktörler de bulunmaktadır ki Türkiye'nin kredi derecelerindeki düşüşün arkasında ağırlıklı olarak ekonomik faktörlerin yattığı düşünülmektedir. Nitekim, 1990’lı yıllardaki kredi düşüşlerinin arkasındaki etken unsur oldukça yüksek seyreden enflasyondur (Erim, 2017, s.7). Bir diğer çalışma olan Yüksel ve Özsarı (2017), 1992-2015 döneminde Türkiye'nin kredi notunu belirleyen baskın faktörün cari işlemler açı̆̆ı olduğunu bulmuşlardır. Bu durum, Türkiye' de iktidar değişimlerinin kredi derecesini olumsuz etkilediği ancak etkinin sınırlı olduğu şeklinde yorumlanabilmektedir.

\section{Tartışma ve Sonuç}

Türkiye yüksek politik devre, bu anlamda yüksek iktidar değişimine ve çeşitli sivil olmayan yönetim dönemlerine sahip bir ülkedir. Bu açıdan Türkiye gibi yüksek politik devre sahip bir ülke için politik devrin sonuçları önem arz etmektedir. Politik devrin sonuçlarından bir tanesi hiç şüphesiz devlet borçları ile ilgilidir. Nitekim çalışmamıza göre, politik devir ile devlet borç göstergeleri arasında önemli ilişkiler mevcuttur.

Politik devrin devlet borçları üzerindeki etkilerini ele alan bu çalışmada politik devrin etkilediği borç göstergeleri dört gruba ayrılmıştır. Bu göstergeler, borç düzeyi (genel devlet borcu/GSYİH), borç krizi (kriz yılları), borç temerrüdü (temerrüt yılları) ve ülkenin kredibilitesinden (kredi notları) oluşmaktadır. Çalışmanın sonucuna göre; (i) Türkiye'de yoğun politik devrin ya- 
şandığı dönemlerin ardından borç düzeyi artışa geçmektedir. Politik istikrarın görüldügü dönemlerde ise borç düzeyleri düşmektedir. (ii) Türkiye'de yoğun politik devrin ardından borç krizi yaşanmakta, krizin ardından ise politik istikrar hüküm sürmektedir. Bu durum toplumun borç krizinin ardından siyasi istikrar istediği şeklinde yorumlanabilmektedir. (iii) Türkiye'de yoğun politik devrin yaşandığı yılların ardından temerrüt sayılarında artış görülmektedir. Temerrüt yıllarında veya temerrüdün ardından ise, nispeten siyasi istikrar yaşanmaktadır. (iv) Türkiye'de politik devir kredi derecelerini olumsuz etkilemektedir ancak etki sinırlıdır.

Çalışmanın sonucu, genel olarak Türkiye ve özelde politika yapıcılar için birtakım öneriler sunmaktadır. Buna göre, Türkiye'de politik devrin yüksek ve bu anlamda siyasi istikrarın düşük olduğu dönemlerin ardından devlet borç göstergelerinde olumsuz gelişmeler yaşanmaktadır. Politik devrin nispeten düşük olduğu dönemlerde ise borç göstergelerinde olumlu gelişmeler yaşanmaktadır. Bu açıdan Türkiye için politik istikrar devlet borç yönetimine katkı yapacaktır. Diğer yandan ülkenin kredibilitesi politik faktörler yanında yoğunlukla ekonomik faktörlerden etkilenmektedir. Bu açıdan politik istikrarın yaşandığı dönemlerde ekonomik göstergelerde iyileşmenin sağlanması son derece elzemdir ve borç yönetimine katkı yapacaktır.

Çalışma, politik devir ve devlet borçları ilişkisini ele alabilecek birçok çalışmaya temel oluşturmaktadır. Çalışmada yer alan uzun dönemli verilerin ampirik olarak analiz edilmesi ise bir yandan literatüre katkı sunarken diğer yandan elde edilen yeni bulgular çalışmaları güçlendirebilecektir. Bu açıdan politik devir ve borç göstergelerinin analizi yeni ampirik çalışmalara zemin hazırlamaktadır. 


\title{
EXTENDED ABSTRACT
}

\section{The Relationship Between Political Turnover and Sovereign Debt in Turkey}

\author{
Mehmet Ela \\ Osmaniye Korkut Ata University
}

Political turnover was represented by different indicators such as leadership turnover and government change. The political turnover, which represents the government change in our study, affects many factors related to economy and society. As a matter of fact, it is possible to talk about the economic, financial and especially social effects of the political turnover. In this context, the political turnover can affect a wide range of factors that concern society, such as investor behavior, trade relations, economic growth, and technological change. One of the factors influenced by the political turnover is undoubtedly events and indicators related to state debt.

Political turnover can affect government borrowing in a variety of ways. The political turnover has an impact on government borrowing, mainly due to the existence of short-sighted (myopic) parties about the possibility of reelection. As a matter of fact, political parties can increase borrowing due to the uncertainty about the future responsibility of the sovereign debt, or the party who wants to affect its successor due to the low probability of being reelected may change the borrowing strategy. The political turnover can lead to debt crises, and because it negatively affects the economic indicators of the pre-default period, it can lead to default in debts through high borrowing costs. On the other hand, high political turnover leads to myopic governments and increases the likelihood of default. This leads to higher borrowing costs for any borrowing level. All of these situations may cause excessive borrowing, debt crises and defaults, while negatively affecting the credibility of countries. In this regard, we divided the debt indicators affected by the political age into four groups. These are, sovereign debt level (general government debt / GDP), debt crisis (crisis years), debt default (default years) and the country's credibility (credit ratings).

Political turnover is particularly important for a country like Turkey with high government change. Except for the recent years, political turnover, 
which is high in Turkey, has led to some important conclusions about the state borrowing. In this regard, in order to analyze the relationship between political turnover and sovereign debt indicators, four sovereign debt indicators which are in relationship with political turnover were identified in the study.

The sovereign debt indicators which are in relationship with political turnover consist of sovereign debt level (general government debt / GDP), debt crisis (crisis years), debt default (default years) and the country's credibility (credit ratings). The study adopted a discursive method supported with graphs and analyzed the relationship of political turnover and sovereign debt indicators between the years of 1960-2019 for Turkey. On the other hand, as an indicator of political turnover, we use government change data. We divided the data for the period of 1960-2019 into three-year periods and used the three-year averages of the data.

According to the result of the study; (i) After the period of intense political turnover, level of debt increases in Turkey. In periods of political stability, debt level decreases. (ii) After the period of intense political turnover, the debt crises are experienced in Turkey and after the debt crisis, political stability prevails. This situation can be interpreted as the society wants political stability after the debt crisis. (iii) In Turkey, after years of intense political turnover, there is an increase in the number of debt defaults. In the period of default or after the default, political stability is experienced. (iv) Political turnover negatively affects credit ratings in Turkey, but the effect is limited.

The results of the study offer some general recommendations for Turkey and especially for policy makers. Accordingly, in Turkey, after periods of high political turnover and in this regard low political stability, there are negative developments in sovereign debt indicators. In the periods when the political turnover is relatively low, there are positive developments in the sovereign debt indicators. For this reason, political stability will contribute to public debt management in Turkey. On the other hand, the credibility of Tukey is mostly affected by economic factors besides political factors. In this respect, it is extremely essential to improve the economic indicators in times of political stability. This will contribute to debt management.

The study forms the basis for many studies that can address the relationship between political turnover and sovereign debt. The potential empirical analysis of long-term data included in the study, on the one hand, contributes 
to the literature, while new findings obtained from econometric results can strengthen the literature. In this respect, analysis of political turnover and debt indicators paves the way for new empirical studies.

\section{Kaynakça / References}

Alesina, A. ve Tabellini, G. (1990). A positive theory of fiscal deficits and government debt. The Review of Economic Studies, 57(3), 403-414.

Alt, J. E., ve Lassen, D. D. (2006). Fiscal transparency, political parties, and debt in OECD countries. European Economic Review, 50(6), 1403-1439.

Amador, M. (2003). A political economy model of sovereign debt repayment. Manuscript, Stanford University.

Asiri, B. K. ve Hubail, R. A. (2014). An empirical analysis of country risk ratings. Journal of Business Studies Quarterly, 5(4), 52.

Balkan, E. M. (1992). Political instability, country risk and probability of default. Applied Economics, 24(9), 999-1008.

Block, S. A. ve Vaaler, P. M. (2004). The price of democracy: sovereign risk ratings, bond spreads and political business cycles in developing countries. Journal of International Money and Finance, 23(6), 917-946.

BoC-BoE Sovereign Default Database (2019). Boc-boe sovereign default database. 10 Ekim 2019 tarihinde https://www.bankofengland.co.uk/working-paper/2019/the-boc-boe-sovereign-default-database-whats-new-in-2019 adresinden erişildi.

Bordo, M. ve Oosterlinck, K. (2005). Do political changes trigger debt default? And do defaults lead to political changes. 01 Kasim 2019 tarihinde http://fordschool.umich.edu/files/BordoOosterlinckPEIF.pdf adresinden erişildi.

Borensztein, E. ve Panizza, U. (2009). The costs of sovereign default. IMF Staff Papers, 56(4), 683-741.

Born, B., Müller, G. J., Pfeifer, J. ve Wellmann, S. (2018). Market discipline? sovereign spreads, fiscal adjustments, and political turnover. 15 Ekim 2019 tarihinde https://pdfs.semanticscholar.org/98bc/0e274a4b9886870aa3c808a69506154f15fa.pdf adresinden erişildi.

Brewer, T. L. ve Rivoli, P. (1990). Politics and perceived country creditworthiness in international banking. Journal of Money, Credit and Banking, 22(3), 357-369. 
Chwieroth, J. M. ve Walter, A. (2010). Financial crises and political turnover: a long run panoramic view. 16 Ekim 2019 tarihinde http://personal.lse.ac.uk/Chwierot/images/Panoramic.pdf adresinden erişildi.

Citron, J. T. ve Nickelsburg, G. (1987). Country risk and political instability. Journal of Development Economics, 25(2), 385-392.

Cole, H. L., Dow, J. ve English, W. B. (1995). Default, settlement, and signalling: Lending resumption in a reputational model of sovereign debt. International Economic Review, 365-385.

Cotoc, J., Johri, A. ve Sosa-Padilla, C. (2018). Debt, defaults and dogma: politics and the dynamics of sovereign debt markets. 14 Ekim 2019 tarihinde https://www.isid.ac.in/ epu/acegd2018/papers/AlokJohri.pdf adresinden erişildi.

Cuadra, G. ve Sapriza, H. (2008). Sovereign default, interest rates and political uncertainty in emerging markets. Journal of international Economics, 76(1), 78-88.

Debortoli, D. ve Nunes, R. C. (2008). Political disagreement, lack of commitment and the level of debt. FRB International Finance Discussion Paper, No. 938.

Dhillon, A. ve Sjostrom, T. (2009). Leader reputation and default in sovereign debt. Warwick Economic Research Papers, No. 886.

Di Bartolomeo, G., Di Pietro, M., Saltari, E. ve Semmler, W. (2018). Public debt stabilization: the relevance of policymakers' time horizons. Public Choice, 177(3-4), 287-299.

Erim, G. (2017). 3 Büyük kredi derecelendirme kuruluşu ve Türkiye'nin notu. KTO Araştırma Raporu.

Franzese, R. J. (2001). The positive political economy of public debt: an empirical examination of the OECD postwar experience. University of Michigan. Ann Arbor, unpublished manuscript.

Furceri, D. ve Zdzienicka, A. (2012). How costly are debt crises? Journal of International Money and Finance, 31(4), 726-742.

Glaurdić, J., Lesschaeve, C. ve Vizek, M. (2019). Consolidated democracy advantage: political instability and sovereign spreads in the EU. Comparative European Politics, 1-23.

Goretti, M. (2005). The Brazilian currency turmoil of 2002: a nonlinear analysis. International Journal of Finance \& Economics, 10(4), 289-306.

Grechyna, D. (2015). Quantifying the impact of political frictions on public policy. MPRA Paper, No. 68918. 
Grilli, V., Masciandaro, D. ve Tabellini, G. (1991). Political and monetary institutions and public financial policies in the industrial countries. Economic Policy, 6(13), 341-392.

Hanusch, M. ve Vaaler, P. (2015). Credit ratings and fiscal responsibility. MFM Discussion Paper, No. 4

Hatchondo, J. C., Martinez, L. ve Sapriza, H. (2009). Heterogeneous borrowers in quantitative models of sovereign default. International Economic Review, 50(4), 1129-1151.

Hatchondo, J. C. ve Martinez, L. (2010). The politics of sovereign defaults. FRB Richmond Economic Quarterly, 96(3), 291-317.

IMF (2020). Historical public debt database. 20 Kasım 2019 tarihinde https:/www.imf.org/external/datamaper/DEBT1@DEBT/OEMDC/ADVEC/WEOWORLD/TUR adresinden erişildi.

Jimenez, B. S. (2011). Management quality and state bond ratings: Exploring the links between public management and fiscal outcomes. International Journal of Public Administration, 34(12), 783-799.

Kohlscheen, E. (2010). Sovereign risk: Constitutions rule. Oxford Economic Papers, 62(1), 62-85.

Krueger, S. ve Walker, R. W. (2008). Divided government, political turnover, and state bond ratings. Public Finance Review, 36(3), 259-286.

Krueger, S. ve Walker, R. W. (2010). Management practices and state bond ratings. Public Budgeting $\mathcal{E}$ Finance, 30(4), 47-70.

Livshits, I., Phan, T. ve Trebesch, C. (2014). Sovereign default and political turnover. 20 Kasim 2019 tarihinde https://www.aeaweb.org/conference/2015/retrieve.php adresinden erişildi.

Lvovskiy L. (2018). Political responsibility for economic crises. 10 Ekim 2019 tarihinde http://eng.beroc.by/webroot/delivery/files/FREEPolicyBriefs_Apr22.pdf adresinden erişildi.

Manasse, P., Roubini, N. ve Schimmelpfennig, M. A. (2003). Predicting sovereign debt crises. IMF Working Paper, No. 03-221.

McGillivray, F. ve Smith, A. (2003). Who can be trusted? Sovereign debt and the impact of leadership change. Department of Politics New York University Working Paper.

Moody's (2019). Ratings -Turkey, government of-. 15 Ocak 2020 tarihinde https://www.moodys.com/credit-ratings/Turkey-Government-of-creditrating-768337 adresinden erişildi. 
Netdata (2020). Hükümet dönemleri. 15 Ocak 2020 tarihinde http://www.netdata.com/netsite/8f03114e/hukumet-donemleri? $\mathrm{p}=3$ adresinden erişildi.

Park, S. (2018). Understanding public sector debt: Financial vicious circle under the soft budget constraint. Public Organization Review, 18(1), 71-92.

Pepinsky, T. B. (2012). The global economic crisis and the politics of non-transitions. Government and Opposition, 47(2), 135-161.

Persson, T. ve Svensson, L. E. (1989). Why a stubborn conservative would run a deficit: Policy with time-inconsistent preferences. The Quarterly Journal of Economics, 104(2), 325-345.

Rivoli, P. ve Brewer, T. L. (1997). Political instability and country risk. Global Finance Journal, 8(2), 309-321.

Scholl, A. (2017). The dynamics of sovereign default risk and political turnover. Journal of International Economics, 108, 37-53.

Smaoui, H., Boubakri, N. ve Cosset, J. C. (2017). The politics of sovereign credit spreads. Emerging Markets Finance and Trade, 53(8), 1894-1922.

Trebesch, C. (2018). Resolving sovereign debt crises: the role of political risk. Oxford Economic Papers, 71(2), 421-444.

Vaaler, P. M., Schrage, B. N. ve Block, S. A. (2005). Counting the investor vote: Political business cycle effects on sovereign bond spreads in developing countries. Journal of International Business Studies, 36(1), 62-88.

Ulusoy, A. (2012). Türkiye'de iç borçlanma. F.Tekin ve Ş. Tosunoğlu (Ed.), Devlet borçları içinde (s. 98-120). Eskişehir: Anadolu Üniversitesi Açıköğretim Fakültesi Yayını.

Wang, K. Y. ve Tu, S. M. (2014). The influence of national leader change on corruption and sovereign rating. Acta Oeconomica, 64(Supplement 2), 79-97.

Yu, S. (2016). The effect of political factors on sovereign default. Review of Political Economy, 28(3), 397-416.

Yüksel, S. ve Özsarı, M. (2017). Türkiye'nin kredi notunu etkileyen faktörlerin Mars yöntemi ile belirlenmesi. Politik Ekonomik Kuram, 1(2), 16-30.

\section{Kaynakça Bilgisi / Citation Information}

Ela, M. (2020). Türkiye'de politik devir ve devlet borçları ilişkisi. OPUSUluslararası Toplum Araştırmaları Dergisi, 16(30), 3110-3133. DOI: 10.26466/opus.702552 